\title{
Labyrinthe
}

$7 \mid 2000$

Numéro 7

\section{Le Crochet de la Cédille}

La littérature chez les scientifiques

\section{Laurence Marie}

\section{(2) OpenEdition}

Journals

Édition électronique

URL : http://journals.openedition.org/labyrinthe/726

DOI : $10.4000 /$ labyrinthe.726

ISSN : 1950-6031

Éditeur

Hermann

\section{Édition imprimée}

Date de publication : 30 octobre 2000

Pagination : 173-175

\section{Référence électronique}

Laurence Marie, « Le Crochet de la Cédille », Labyrinthe [En ligne], 7 | 2000, mis en ligne le 20 avril 2005, consulté le 19 avril 2019. URL : http://journals.openedition.org/labyrinthe/726 ; DOI : 10.4000/

labyrinthe.726

Ce document a été généré automatiquement le 19 avril 2019

Propriété intellectuelle 


\title{
Le Crochet de la Cédille
}

\author{
La littérature chez les scientifiques
}

\section{Laurence Marie}

«Un crochet, tout le monde sait ce que c'est. Une cédille, c'est moins commun, mais beaucoup en ont déjà vu. Vous savez, ce joli petit truc inutile qui pendouille sous la lettre C. Bon. Mais Le Crochet de la Cédille, qu'est-ce donc que cette chose-là ? Eh bien, c'est un fanzine proposant principalement des nouvelles mais aussi des images, sur un thème. » Voilà comment Sandrine Lyonnard, Gilles Prigent, thésards du Commissariat à l'Énergie Atomique, et Emmanuel Rinck, un de leurs copains de lycée, nous font entrer dans l'univers de leur fanzine, en ouverture du numéro zéro d'avril 1999. Un nom accrocheur pour un fanzine atypique, qui regroupe des textes écrits principalement par des scientifiques. 


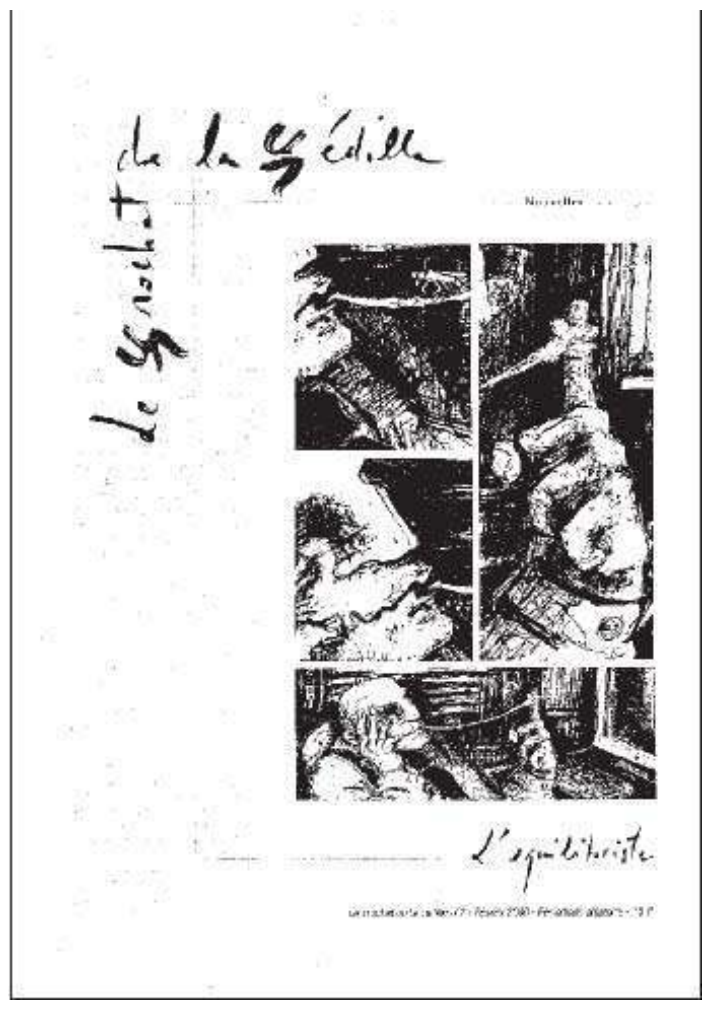

2 «Parce qu'ils sont souvent autodidactes, les scientifiques ont des références littéraires différentes. Nous voulions absolument nous éloigner des sentiers philosophicointellectuels ", explique Sandrine, qui travaille actuellement en laboratoire sur les applications du latex. Rien n'est en effet plus éloigné de l'esprit de sérieux que Le Crochet de la Cédille : «On insiste sur le mot de fanzine, qui se distingue aisément de son cousin magazine par un amateurisme revendiqué, par la bonne humeur qui prévaut à sa conception ». "Notre idée de base est de regrouper des textes et des images, autour d'un thème qui change à chaque numéro, et qui ne doit pas être un poncif », explique Gilles. Car il ne s'agit pas de publier ses fonds de tiroir, mais de plancher à partir d'un thème précis, communiqué deux mois à l'avance aux heureux inscrits sur la liste internet du Crochet. Aucune sélection n'est prévue pour l'instant : «Il arrive qu'aucun de nous trois n'aime une nouvelle qui plaît pourtant aux lecteurs. » Revers de la médaille, les textes sont de qualité inégale.

Le premier thème proposé, « Passages cloutés ", a laissé libre cours aux états d'âme. Les passages cloutés cristallisent les tentations suicidaires, symbolisent les «ruelles obscures » de l'enfance de Léo, sont arpentés méthodiquement par un Amédée en quête du sens : «Le macadam repose sur quelque chose ». «L'équilibriste », thème du second numéro, a davantage interpellé l'imaginaire de ceux qui se sont prêtés au jeu. Bilan du ramassage des copies : de brèves nouvelles souvent humoristiques, mais aussi des poèmes - "Allongé entre le Ciel et la Terre ", "L'Équilibriste du désir »-, une bande dessinée rigolote - «Une patate en interligne » -, et un roman-photo sous forme de variation sur Amok de Stefan Zweig. Car Le Crochet de la Cédille, ce n'est pas seulement des textes : au thème proposé répondent également des reproductions de peintures de jeunes artistes contemporains, des photos et les illustrations de Sandrine Lyonnard (qui expose par ailleurs au Salon d'Automne). Au fil des vernissages, le fanzine s'est ouvert à des artistes, peintres ou étudiants en arts plastiques, séduits par ce concept d'improvisation libre sur un thème imposé. 
4 On attend la parution du numéro 3, décliné sur «Bon appétit ». Prévus au menu : «Plat du jour, cuisine internationale (tambouille entre nations) », «D'eux à moi », l'histoire d'un écrivain raté qui cherche l'inspiration en cuisinant les feuillets volés chez des écrivains contemporains, ou encore "la Chèvre et le légionnaire ", nouvelle mettant en scène une étrange séance de cannibalisme. Le premier né du Crochet a été conçu de nuit, en toute illégalité, dans le laboratoire d'un grand institut dont nous tairons le nom. Pour les suivants, la bande des trois a cependant jugé plus prudent de s'adresser à un imprimeur.

Numéro 2, février 2000 : « L'équilibriste » Éditorial

5 « Vous avez dit apériodique?

6 Neuf mois ont passé depuis la parution du premier numéro du Crochet de la Cédille, et voilà enfin le numéro $2 . .$. une grossesse difficile pour ainsi dire mais le bébé se porte bien, merci. Il pèse 55 pages et regorge de textes divers - avec maintenant des poèmes - et de nombreuses illustrations originales et variées (peintures, dessins, roman-photo...). Sur la forme, il présente indiscutablement un air de famille avec son grand frère. Sur le fond, le principe reste celui de la figure imposée. Cependant, nouveau numéro, nouveau thème : nous avons donc quitté le bitume poussiéreux des passages cloutés pour la corde suspendue de l'équilibriste. Plus facile ? Rien n'est moins sûr. En tout cas le résultat est là : de l'intrigue policière à la peinture politique, en passant par le voyage initiatique ou la descente en Enfer, venez arpenter nos cordes, et selon la formule consacrée, faites-vous votre opinion. Reste que le Crochet de la Cédille poursuit sa route, entre ciel et terre, et ça, c'est déjà une bonne nouvelle.

7 Les trois têtes de clou »

8 Le Crochet de la Cédille

9 63, rue Greneta 75002 Paris

10 http://Lecrochet. free. fr

110142336860 (Sandrine) / 0155766637 (Gilles) / e. rinck(at)free. fr (Emmanuel). 